
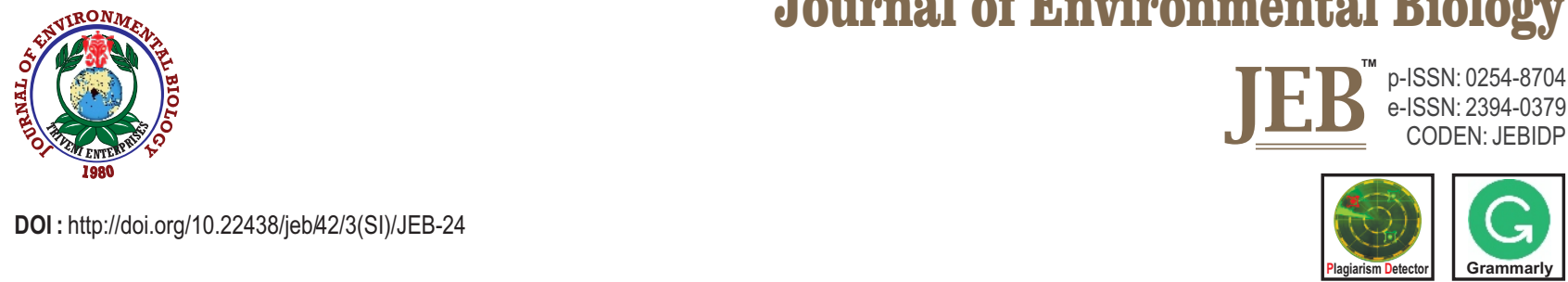

\title{
Truss network based morphometric and meristic variations among south-western populations of Macrognathus aculeatus in Bangladesh
}

\author{
M. Sarower-E-Mahfuj ${ }^{1 *}$, S.K. Das ${ }^{2}$, K.N. Azad ${ }^{3}$, A.K. Paul ${ }^{4}$, I. Hoshan ${ }^{5}$, S. Sultana ${ }^{6}$ and M. Biswas ${ }^{1}$ \\ ${ }^{1}$ Department of Fisheries and Marine Bioscience, Jashore University of Science and Technology, Jashore, 7408, Bangladesh \\ ${ }^{2}$ Department of Earth Sciences and Environment, Faculty of Science and Technology, Universiti Kebangsaan Malaysia, 43600 Bangi, Malaysia \\ ${ }^{3}$ Department of Aquaculture, Faculty of Fisheries, Bangladesh Agricultural University, Mymensingh, 2202, Bangladesh \\ ${ }^{4}$ Department of Fisheries, Faculty of Agriculture, University of Rajshahi, Rajshahi, 6205, Bangladesh \\ ${ }^{5}$ Department of Fisheries Biology and Genetics, Faculty of Fisheries, Hajee Mohammad Danesh Science and Technology University, Dinajpur, \\ 5200 , Bangladesh \\ ${ }^{6}$ Fisheries and Marine Resource Technology Discipline, Khulna University, Khulna, 9208, Bangladesh \\ *Corresponding Author Email : sa.mahfuz@gmail.com
}

\section{Abstract}

Aim: Landmark-based truss network system was applied to examine the morphometric and meristic differences among four different populaces of Macrognathus aculeatus namely; Dhakuriabeel, Jashore (DBJ); Arial Kha River, Madaripur (AKRM); Nabaganga River, Jhenaidah (NRJ); Kopotakkha River, Jashore (KRJ) in Bangladesh.

Methodology: Completely 80 samples of $M$. aculeatus were collected (20 individuals from each population) for this study. Six meristic characters, 6 morphometric characters and 15 truss-based morphometric characters were measured for one-way analysis of variance (ANOVA) and Tukey-HSD post hoc test. Discriminant function analyses were also performed by using morphometric and truss-based morphometric characters to detect potential characters responsible for population separation.

Results: ANOVA results revealed significant differences among three meristic characters, 6 morphometric and 10 truss-based morphometric characters. By using both morphometric and truss dimensions, the first discriminant function analysis (DFA) resulted for $46.3 \%$, the second DF resulted for $36.6 \%$ and the third DF resulted for $17.1 \%$ among-group variability. The populations were clearly aggregated among four populations in the discriminant space. Considering the morphometric and truss measurements, $100 \%, 94.4 \%$, $91.7 \%$ and $84.2 \%$ of unique grouped cases were appropriately classified in KRJ, AKRM, DBJ and NRJ, respectively. In Euclidian dendrogram, where first cluster formed by AKRM and second cluster formed by two populations DBJ and NRJ and finally KRJ formed another sub cluster with DBJ.

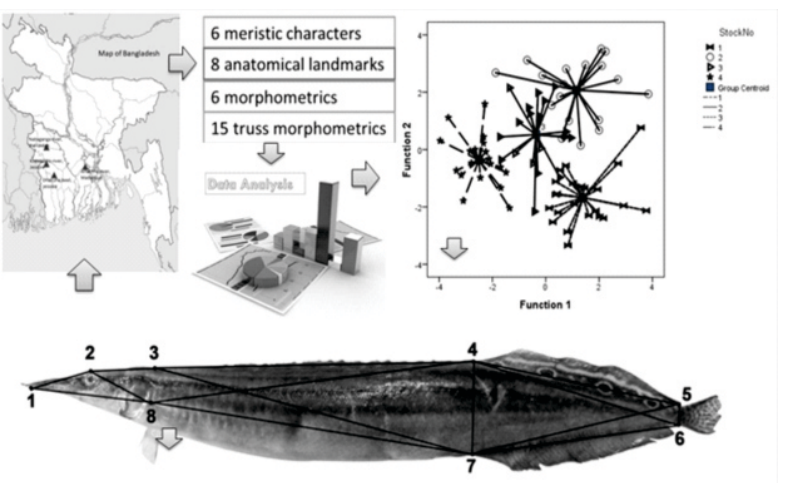

Interpretation: The baseline information derived from the present study would be useful for appropriate conservation of $M$. aculeatus populations as well as for the researchers for further investigation.

Key words: Landmarks, Macrognathus aculeatus, Meristic variations, Morphometric, Truss morphometrics

How to cite : Sarower-E-Mahfuj, M., S.K. Das, K.N. Azad, A.K. Paul, I. Hoshan, S. Sultana and M. Biswas: Truss network based morphometric and meristic variations among south-western populations of Macrognathus aculeatus in Bangladesh. J. Environ. Biol., 42, 887-894 (2021). 


\section{Introduction}

Phenotypic variability among fish populations (which is caused by environmental and genetic-environmental interactions) can be described through examining external morphology (morphometric and meristic counts) across the fish body (Kaneko, 2009). Various methods such as truss network systems, conventional tags, parasites as ordinary biomarkers, otolith chemistry and molecular techniques have been widely used for resolving stock identification. Among all the aforementioned techniques, morphometric characters are one of the most regularly used and cost-effective approaches. Thus, morphometric and meristic characters are influential methods for determining discreteness and interactions among fish populations globally (Melvin et al., 1992; Pathak et al., 2013) and these techniques have been extensively used in all aspects of fisheries research (i.e. stock identification, stock delineation, phenotypic variation, ecological and evolutionary studies) (Barriga-Sosa et al., 2004; Pinheiro et al., 2005; Chaklader et al., 2019; Hanif et al., 2019). Landmark-based truss networks are some arbitrarily selected distances on a fish body that is used for measuring of body shape of a single species (Swain and Foote, 1999). Nevertheless, truss network is a technique that can provide supplementary taxonomic information to enhance species identification (Strauss and Bond, 1990). Hence, truss network systems can be considered as powerful tools for stock identification as well as detecting morphological variations among population of a species (Strauss and Bookstein, 1982).

The peacock eel or spiny eel, Macrognathus aculeatus is a specie of order Mastacembeli formes. It is widely distributed in South East Asian countries (Saha, 2007), including Bangladesh. This fish has gained much popularity due to its high economic value as well as high nutritive value as a table fish. The feeding habit of $M$. aculeatus is detritus and insect larvae feeder. It is an occupant of muddy bottom of any types of freshwater sources. According to IUCN-Bangladesh (2015), M. aculeatus is a near threatened species. Though this fish species has high nutritious value and high customer appeal but information regarding on the biology of this species is scarce. Recent studies have reported that this specie is facing a major bottleneck due to several anthropogenic activities and climate change in Bangladesh (Ahmed and Akhter, 2008). Keeping in view the above, the present study was conducted to examine the external phenotypes (morphological and meristic variations) of wild populations of $M$. aculeatus inhabiting from South-Western region in Bangladesh.

\section{Materials and Methods}

Sampling: A total of 80 individuals of $M$. aculeatus were collected from four different freshwater sources viz., DBJ: Dhakuriabeel, Jashore; AKRM: Arial khan River, Madaripur; NRJ: Nabaganga River, Jhenidah and KRJ: Kopotakkha river, Jashore and immediately preserved in ice box. The samples were immediately brought to the Laboratory of Fish Biology and Aquaculture, Department of Fisheries and Marine Bioscience, Jashore University of Science and Technology, Jashore, Bangladesh for meristic counts and morphometric measures. The samples were collected during September to November 2017.

Meristic counts: Six meristic characters viz. number of dorsal spiny rays (DSR), number of dorsal soft fin rays (DFR), number of caudal fin rays (CFR), number of anal fin rays (AFR), number of pelvic fin rays (PELFR), and number of black dots on dorsal fins (NOBD) of each individual was counted with needles and glass lens.

Morphometric measurements: Firstly, the samples were gently removed from icebox and washed under flowing tap water. The samples were positioned on a flat paper as a background with an identification code. Next, the fins and fin rays were erected to mark the different landmarks on the fish body. After that, digital image of each individual was collected by using a cyber shot DSC-W730 digital camera (Sony, China) with a liner scale marked in centimeter scale (Cadrin and Fridland, 1999). Finally, all digital images were stored in computer systems and 7 morphometric parameters were measured from left to right directions across the fish body with software platform tpsDig2 v2.1 (Rohlf, 2006) (Table 2).

The morphometric characters of $M$. aculeatus studied are as follows: Total length (TL) - Distance from the tip of the upper jaw to the end point of caudal fin ray; Standard length $(S L)$ Distance from the tip of the upper jaw to the end of the vertebral column; Body depth (BD) - Maximum depth vertically measured from the base of the middle dorsal fin ray; Upper jaw length (UJL) Straight line measurement between the snout tip and posterior edge of maxilla; Lower jaw length (LJL) - Straight line measurement between the snout tip and posterior edge of mandible; Head depth (HD) - Vertical distance at the at the post position of the operculum; Inter orbital (IO) - Distance between dorsal side of both eyes.

The truss protocol was constructed by fixing 8 landmarks and truss measurements were assembled by joining them to form 15 truss morphometric networks (Fig. 1). The withdrawal of truss distances from digital images of specimens were extracted using a software platform, tpsDig2v 2.1 (Rohlf, 2006).

Statistical analyses: Morphometric parameters are continuous variables and, hence, these variables are suitable for multivariate analyses. Prior to the analysis, the characters of physical sizes of individual fish were excluded by standardizing the size according to Elliot etal. (1995).

$$
M_{\mathrm{adj}}=M\left(L_{s} / L_{0}\right)^{b}
$$

Where, $M$ is the unique measurement; $M_{\text {adj }}$ is the size adjusted 


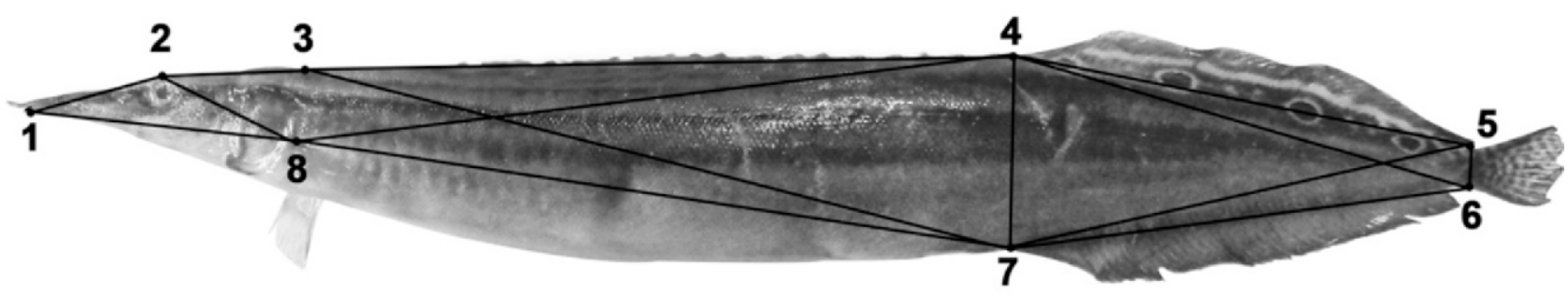

Fig. 1 : Position of 8 anatomic landmarks and truss morphometrics (containing 15 truss characters) created from the left view of $M$. aculeatus. The description of landmarks are as follows: 1: Forward tip of the lower snout, 2: Forward dorsal medial edge of the orbital socket, 3: Forehead (end of the frontal bone), 4: Foundation of the soft dorsal fin, 5: Dorsal basis of the caudal fin, 6: Ventral source of the caudal fin, 7: Origin of anal fin and 8: Derivation of pectoral fin.

measurement; $L_{0}$ is the total length of fish and $L_{s}$ is the overall mean of total length for all fish from all samples. Parameter $b$ : the slope of regression of $\log \mathrm{M}$ on $\log \mathrm{L}_{0}$, using all fish individuals. Meristic and morphometric variables were compared using oneway analysis of variance followed by Tuckey-HSD post hoc tests. However, one-way analysis followed by Tukey-HSD post hoc tests cannot confer population variations by using meristic and morphometric characters. To detect the specific parameters which are responsible to exhibit phenotypic divergences among the four populations we analyzed univariate statistics. i.e. discriminant function analysis (DFA). In this case of DFA analysis, we used only morphometric parameters. DFA analysis mainly focused on the point of likeness between the samples in general investigation and the comparative rank of each dimension. Population centroids with $5 \%$ significance ellipses resulted from DFA analyses were used to envisage connections amongst the individual of all groups. Population-wise classification results were conducted with DFA. A dendrogram was drawn based on the morphometric and truss distances of the population. All statistical analyses were set up at 5\% significant level by using SPSS 21 (SPSS, Chicago, IL, USA).

\section{Results and Discussion}

The one-way ANOVA tests of six meristic characters showed that three characters viz., DFR $(F=6.348$ and $P$ value $<$ 0.05), CFR ( $F=9.430$ and $P$-value $=0.00)$ and AFR (3.433 and $P$ value $<0.00)$ found significant differences. Whereas, the remaining three characters viz., DSR $(F=0.435$ and $P$-value $>$ 0.05), PELFR ( $F=0.631$ and $P$-value $>0.05)$ and NOBD ( $F=$ 0.824 and $P$-value $>0.05$ ) didn't confer significant differences among the four populations (Table 3). These phenomena may be caused due to similar abiotic, biotic factors as well as similar ecohydrological parameters such as similar motions of water current flow, duration of day degree temperature and water quality parameters etc. In this regard, we didn't measure the abiotic, biotic and other water quality parameters. The DBJ population significantly differed from the AKRM, NRJ and KRJ populations for instance of DFR character. In the feature of CFR character,
DBJ and NRJ populaces totally showed significant from the AKRM and KRJ populaces and displayed intermediate between the two populaces of DBJ and NRJ separately. Additionally, the $\mathrm{NRJ}$ and KRJ populations were entirely distinguishable from the $\mathrm{DBJ}$ and AKRM for AFR character.

In case of morphometric characters, $S L(F=7.015$ and $P$ value $=0.00), \mathrm{BD}(F=6.561$ and $P$ value $<0.05), \mathrm{UJL}(F=23.683$ and $P$ value $=0.00)$, $L J L(F=5.163$ and $P$ value $<0.05), H D(F=$ 19.029 and $P$ value $=0.000)$ and $I O(F=4.459$ and $P$ value $<0.05)$ showed significant differences (Table 3 ). Moreover, 10 trussbased morphometric characters for instance, 1-2 ( $F=4.692$ and $P$ value $<0.000), 2-3$ ( $F=11.792$ and $P$ value $<0.000), 6-7$ ( $F=$ 5.498 and $P$ value $<0.05), 7-8(F=4.725$ and $P$ value $<0.05), 1-8$ $(F=3.291$ and $P$ value $<0.05), 3-8(F=14.150$ and $P$ value $=$ $0.000), 3-7(F=5.640$ and $P$ value $<0.05), 4-6(F=5.429$ and $P$ value $<0.05), 4-8(F=6.357$ and $P$ value $<0.05)$ and 5-7 ( $F=$ 6.656 and $P$ value $=0.00$ ) showed highly significant differences, whereas five truss-based morphometric charactersfor instance, 3-4 $(F=14.150$ and $P$ value $>0.05), 4-5(F=14.150$ and $P$ value $=$ $0.05), 5-6(F=14.150$ and $P$ value $=0.05), 2-8(F=14.150$ and $P$ value $=0.05), 4-7(F=14.150$ and $P$ value $=0.05)$ didn't demonstrate any significant differences among the four populations (Table 3).

The NRJ and KRJ populations showed highly significant difference than AKRM population, while DBJ population formed intermediate between NRJ and KRJ populations. In case of BD character, the NRJ population demonstrated significant disparity than AKRM population whereas KRJ population demonstrated inbetween DBJ and NRJ populations as well as DBJ population demonstrated intermediate between AKRM and KRJ populations, respectively. Additionally, the HD, 2-3, 3-8, 4-8, 1-8 and 6-7 characters showed significant differences in NRJ and KRJ populations than the DBJ and AKRM populations. Moreover, the 5-7, 4-6, 3-7 and 7-8 characters ascertained significant differences in DBJ, NRJ and KRJ populations than the AKRM population. Similarly, the AKRM population exhibited highly significant difference than the DBJ, NRJ and KRJ populations for 
the truss-based characterof 1-2. Correspondingly, the DBJ, AKRM and NRJ populations ascertained significant deviation than the KRJ population for the character UJL. Moreover, the IO and LJL characters showed significant differences in AKRM and NRJ populations than the DBJ and KRJ populations, respectively.

The present study showed substantial distinction among the four populations of $M$. aculeatus in Bangladesh in terms of meristic and morphometric characters. Three meristic counts viz., DFR, CFR and AFR showed significant disparities among the six meristic counts. These results are completely similar as previously conducted in Macrognathuspancalus(Mahfuj et al., 2019) for the characters of CFR and PELFR where they analyzedKruskal-Walis test rather than ANOVA with Tukey-HSD post hoc test. In a distinct study, substantial variances were also found in DFR and AFR whereas insignificant results were created in remaining meristic characters of Mesopotamian Mastacembelus mastacembelus populations among three locations of the Karakay pool, the Tohma creek and the Tigris waterway (Çakmak and Alp, 2010). Moreover, researchers only assessed meristic counts and they outlined merely descriptive statistics of the Mastacemblidae family namely, (Sultana et al., 2017) in Macrognathus aculeatus, (Plamoottil and Abraham, 2015) in Macrognathusalbus, (Mahmud et al., 2015) and (Narejo et al., 2003) in Mastacembelus armatus. According to Waldman (2005) meristic parameters are worthwhile for delineating stock identification because they specify the initial development and growth of an organism. However, these phenotypic disparities are completely or partially depend on the genetics and environmental conditions during their life histories (Swain et al., 2005). Abiotic parameters for instance, fluctuations of temperature, salinity, dissolved oxygen, nurturing density, radiation, and degree of day light, geographical locations are the major cause of meristic disparities (Hubbs, 1922; Vladykov, 1934; McHugh, 1954; Leary et al., 1991; Lindsey, 1988; Kashefi et al., 2012).

Discriminant function analysis (DFA) formed three discriminant tasks (DF1, DF2 and DF3) for both morphometric

Table 3 : Descriptive statistics of meristic and morphometric characters of $M$. aculeatus from freshwater sources in Bangladesh

\begin{tabular}{|c|c|c|c|c|c|c|}
\hline & DBJ & AKRM & NRJ & KRJ & $F$ & P-value \\
\hline \multicolumn{7}{|c|}{ Meristic characters } \\
\hline DSR & $18.62 \pm 1.61$ & $19.16 \pm 1.94$ & $18.84 \pm 1.25$ & $19.10 \pm 2.04$ & 0.435 & 0.728 \\
\hline DFR & $50.83 \pm 4.42 a$ & $46.77 \pm 3.93 b$ & $46.31 \pm 2.86 b$ & $46.90 \pm 4.21 b$ & 6.348 & $0.001^{*}$ \\
\hline CFR & $13.41 \pm 2.14 \mathrm{a}$ & $11.50 \pm 1.33 b c$ & $10.94 \pm 1.43 c$ & $12.30 \pm 1.21 a b$ & 9.430 & $0.000^{*}$ \\
\hline AFR & $47.33 \pm 4.50 b$ & $47.88 \pm 3.78 b$ & $50.47 \pm 3.35 a$ & $50.45 \pm 3.34 a$ & 3.433 & $0.021^{*}$ \\
\hline PELFR & $18.75 \pm 2.66$ & $14.00 \pm 2.19$ & $13.89 \pm 1.72$ & $13.70 \pm 1.38$ & 0.631 & 0.597 \\
\hline NOBD & $3.54 \pm 1.21$ & $3.94 \pm 0.99$ & $3.47 \pm 1.07$ & $3.40 \pm 1.27$ & 0.824 & 0.485 \\
\hline \multicolumn{7}{|c|}{ Morphometric characters } \\
\hline SL & $12.82 \pm 0.56 \mathrm{ab}$ & $12.12 \pm 1.32 b$ & $13.68 \pm 1.60 \mathrm{a}$ & $13.30 \pm 0.63 a$ & 7.015 & $0.000^{*}$ \\
\hline $\mathrm{BD}$ & $1.55 \pm 0.18 b c$ & $1.47 \pm 0.21 \mathrm{c}$ & $1.72 \pm 0.22 \mathrm{a}$ & $1.66 \pm 0.10 \mathrm{ab}$ & 6.561 & $0.001^{*}$ \\
\hline UJL & $1.14 \pm 0.20 \mathrm{a}$ & $1.07 \pm 0.22 \mathrm{a}$ & $1.11 \pm 0.032 a$ & $0.77 \pm 0.01 b$ & 23.683 & $0.000^{*}$ \\
\hline LJL & $0.44 \pm 0.08 b$ & $0.47 \pm 0.10 \mathrm{a}$ & $0.49 \pm 0.04 a$ & $0.39 \pm 0.08 b$ & 5.163 & $0.003^{*}$ \\
\hline$H D$ & $0.66 \pm 0.62 b$ & $0.69 \pm 0.007 \mathrm{~b}$ & $0.81 \pm 0.08 a$ & $0.76 \pm 0.04 a$ & 19.029 & $0.000^{*}$ \\
\hline 10 & $0.36 \pm 0.06 b$ & $0.45 \pm 0.06 a$ & $0.42 \pm 0.18 a$ & $0.34 \pm 0.05 b$ & 4.459 & $0.001^{*}$ \\
\hline $1-2$ & $0.71 \pm 0.10 \mathrm{~b}$ & $0.86 \pm 0.20 a$ & $0.79 \pm 0.13 b$ & $0.74 \pm 0.09 b$ & 4.692 & $0.005^{*}$ \\
\hline $2-3$ & $2.00 \pm 0.38 b$ & $2.07 \pm 0.27 b$ & $2.51 \pm 0.41 \mathrm{a}$ & $2.65 \pm 0.57 a$ & 11.729 & $0.000^{*}$ \\
\hline $3-4$ & $5.48 \pm 0.78$ & $5.19 \pm 0.82$ & $5.57 \pm 0.88$ & $5.11 \pm 0.56$ & 1.569 & 0.204 \\
\hline 4-5 & $3.93 \pm 0.87$ & $3.28 \pm 0.43$ & $3.87 \pm 0.88$ & $3.82 \pm 0.88$ & 2.646 & 0.055 \\
\hline $5-6$ & $0.32 \pm 0.54$ & $0.27 \pm 0.04$ & $0.33 \pm 0.05$ & $0.49 \pm 0.08$ & 1.015 & 0.391 \\
\hline $6-7$ & $3.92 \pm 0.35 b$ & $3.62 \pm 0.52 b$ & $4.12 \pm 0.71 a$ & $4.27 \pm 0.44 a$ & 5.498 & $0.002^{*}$ \\
\hline $7-8$ & $6.04 \pm 0.81 a$ & $5.36 \pm 1.29 b$ & $6.68 \pm 1.11 a$ & $5.84 \pm 1.13 a$ & 4.725 & $0.004^{*}$ \\
\hline $1-8$ & $1.83 \pm 0.83 b$ & $2.11 \pm 0.25 b$ & $2.03 \pm 0.25 a$ & $1.98 \pm 0.26 a$ & 3.291 & $0.025^{*}$ \\
\hline $2-8$ & $1.42 \pm 0.26$ & $1.49 \pm 0.19$ & $1.58 \pm 0.16$ & $1.54 \pm 0.18$ & 2.467 & 0.068 \\
\hline 3-8 & $1.07 \pm 0.21 b$ & $1.07 \pm 0.21 b$ & $1.46 \pm 0.35 a$ & $1.49 \pm 0.29 a$ & 14.150 & $0.000^{*}$ \\
\hline $3-7$ & $5.69 \pm 0.64 a$ & $5.02 \pm 0.64 b$ & $5.73 \pm 0.80 a$ & $4.18 \pm 0.27 b$ & 5.640 & $0.002^{*}$ \\
\hline 4-6 & $4.06 \pm 0.87 a$ & $3.38 \pm 0.44 b$ & $4.04 \pm 0.81 a$ & $4.18 \pm 0.27 a$ & 5.429 & $0.002^{*}$ \\
\hline $4-7$ & $1.72 \pm 0.42$ & $1.50 \pm 0.24$ & $1.82 \pm 0.61$ & $1.67 \pm 0.15$ & 2.030 & 0.117 \\
\hline $4-8$ & $6.24 \pm 0.56 b$ & $5.83 \pm 0.85 b$ & $6.88 \pm 0.98 a$ & $6.33 \pm 0.48 a$ & 6.357 & $0.001^{*}$ \\
\hline $5-7$ & $3.99 \pm 0.35 a$ & $3.53 \pm 0.47 b$ & $4.10 \pm 0.77 a$ & $4.22 \pm 0.27 a$ & 6.656 & $0.000^{*}$ \\
\hline
\end{tabular}

Values are presented as mean $\pm S D$. Different small superscripts in each row differs the values of meristic, morphometric and truss distances; $F$ : $F$ Statistics in one-way analysis of variance (ANOVA). ${ }^{*} \mathrm{P}<0.05$; DBJ: Dhakuriabeel, Jashore; AKRM: Arial khan River, Madaripur; NRJ: Nabaganga River, Jhenidah and KRJ: Kopotakkha river, Jashore 
Table 4 : Pooled within group correlations between discriminant variables of M. aculeatus

\begin{tabular}{llll}
\hline Characters & DF1 (46.3\%) & DF2 (36.6\%) & DF3 (17.1\%) \\
\hline UJL & $0.551^{*}$ & -0.013 & 0.426 \\
$3-8$ & $-0.423^{*}$ & 0.020 & 0.329 \\
$2-3$ & $-0.404^{*}$ & 0.050 & 0.215 \\
$6-7$ & $-0.244^{*}$ & -0.144 & 0.156 \\
$5-6$ & $-0.114^{*}$ & -0.049 & -0.047 \\
$1-2$ & 0.038 & $0.299^{*}$ & 0.013 \\
$4-6$ & -0.155 & $-0.257^{*}$ & 0.149 \\
IO & 0.112 & $0.254^{*}$ & 0.110 \\
$1-8$ & -0.046 & $0.250^{*}$ & 0.025 \\
$5-7$ & -0.221 & $-0.230^{*}$ & 0.185 \\
$4-5$ & -0.051 & $-0.196^{*}$ & 0.150 \\
HD & 0.159 & $0.583^{*}$ \\
$4-8$ & -0.389 & -0.085 & $0.461^{*}$ \\
$7-8$ & -0.121 & -0.107 & $0.412^{*}$ \\
SL & -0.043 & -0.126 & $0.383^{*}$ \\
$3-7$ & -0.206 & -0.213 & $0.358^{*}$ \\
BD & 0.065 & -0.067 & $0.357^{*}$ \\
LJL & -0.229 & 0.155 & $0.300^{*}$ \\
$4-7$ & 0.177 & -0.112 & $0.237^{*}$ \\
$3-4$ & -0.034 & -0.062 & $0.208^{*}$ \\
$2-8$ & 0.073 & 0.113 & $0.169^{*}$ \\
\hline
\end{tabular}

and truss characters, where first DF contributed $46.3 \%$, the second DF contributed $36.6 \%$ and third DF contributed for $17.1 \%$ among group variability and together they explained $100 \%$ of the total among group variability (Table 4). Pooled within-group correlations between discriminant variables and DFs exposed that among six morphometric measurements, one-dimension UJL dominantly paid to the first DF, similarly one dimension 10

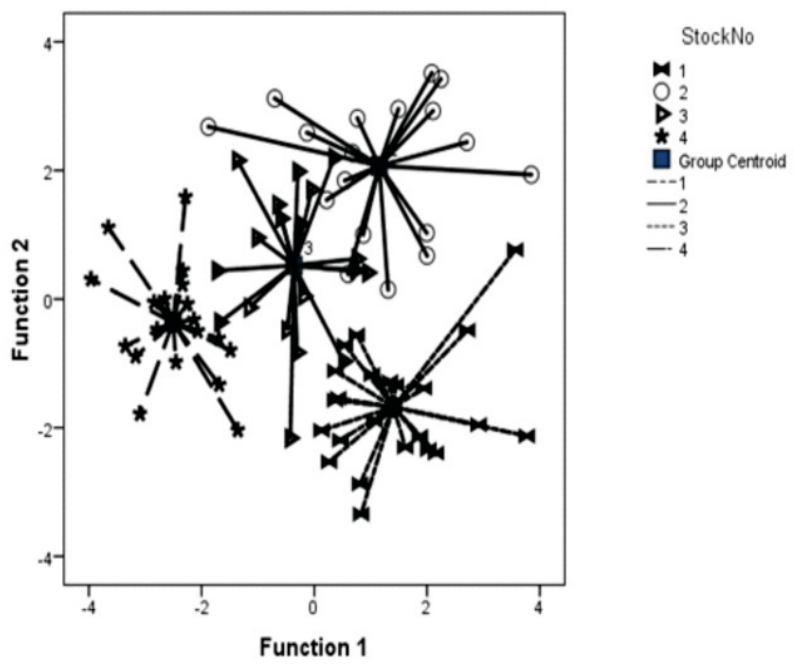

Fig. 2 : Bi-Plot orientation of discriminant function scores using morphometric measurements of $M$. aculeatus. 1. DBJ: Dhakuriabeel, Jashore; 2. AKRM: Arial khan River, Madaripur; 3. NRJ: Nabaganga River, Jhenidah and 4. KRJ: Kopotakkha river, Jashore. underwritten to the second DF and the residual four dimensions paid to the third DF (Table 4). Amongst the fifteen truss-based morphometric dimensions four parameters (3-8, 2-3, 6-7 and 5-6) dominantly paid to the first DF , five dimensions (1-2, 4-6, 1-8, 5-7 and 4-5) also paid to the second DF and the residual six measurements (4-8, 7-8, 3-7, 4-7, 3-4 and 2-8) paid to the third DF (Table 4). In bi-plot orientation from DFA analysis showed a vibrant overlying among the populations for both morphometric and truss measurements in changing notches. This outcome revealed clear aggregation amongst four populations (Fig. 2).

Correct and cross-validation results were aggregately obtained from DFA analysis. Correct classification test showed that $92.5 \%$ of the individuals fit into respective four populations. Among the four populations, percent fitness was observed in KRJ followed by $94.4 \%$ in AKRM, $91.7 \%$ in DBJ and $84.2 \%$ in NRJ population, respectively. Furthermore, the maximum heterogeneities were observed in NRJ (84.2\%) population with DBJ (10.5\%) and AKRM (5.3\%) populations in their respective ratios. Cross-validation results showed that $71.3 \%$ individuals were categorized into their original populations. The average contributions were categorized through ascending orders in the following populations namely, DBJ (83.3\%), KRJ (78.9\%), NRJ $(68.4 \%)$ and AKRM (50\%) respectively. From this classification results it could be concluded that the populations were highly intermingled in populations level through cross-validated analysis whilst the individuals were separated individually in populations level through original classification analysis.

Euclidian dendrogram was arranged based on the 
Table 5 : Classification outcomes of DFA obtained from morphometric characters of M. aculeatus.DBJ: Dhakuriabeel, Jashore; AKRM: Arial khan River, Madaripur; NRJ: Nabaganga River, Jhenidah and KRJ: Kopotakkha river, Jashore

\begin{tabular}{|c|c|c|c|c|c|c|}
\hline \multicolumn{7}{|c|}{ Predicted group membership } \\
\hline & & DBJ & AKRM & NRJ & KRJ & Total \\
\hline \multirow[t]{4}{*}{ Original a $(\%)$} & DBJ & $22(91.7 \%)$ & $1(4.2 \%)$ & $1(4.2 \%)$ & 0 & $24(100 \%)$ \\
\hline & AKRM & $1(5.6 \%)$ & $17(94.4 \%)$ & 0 & 0 & $18(100 \%)$ \\
\hline & NRJ & $2(10.5 \%)$ & $1(5.3 \%)$ & $16(84.2 \%)$ & 0 & $19(100 \%)$ \\
\hline & KRJ & 0 & 0 & 0 & $19(100 \%)$ & $19(100 \%)$ \\
\hline \multirow[t]{4}{*}{ Cross-validated b (\%) } & DBJ & $20(83.3 \%)$ & $1(4.2 \%)$ & $3(12.5 \%)$ & 0 & 24 \\
\hline & AKRM & $4(22.2 \%)$ & $9(50 \%)$ & $3(16.7 \%)$ & $2(11.1 \%)$ & 18 \\
\hline & NRJ & $2(10.5 \%)$ & $2(10.5 \%)$ & $13(68.4 \%)$ & $2(10.5 \%)$ & 19 \\
\hline & KRJ & $2(10.5 \%)$ & 0 & $2(10.5 \%)$ & $15(78.9 \%)$ & 19 \\
\hline
\end{tabular}

a $92.5 \%$ of unique grouped cases appropriately classified; $b 71.3 \%$ of cross-validated grouped cases appropriately categorized.

Dhakuria Beel, Joshore

(DBJ)

Kapotakho River, Joshore (KRJ)

Nabaganga River, Jhenaidah (NRJ)

Arial Kha River, Madaripur (AKRM)

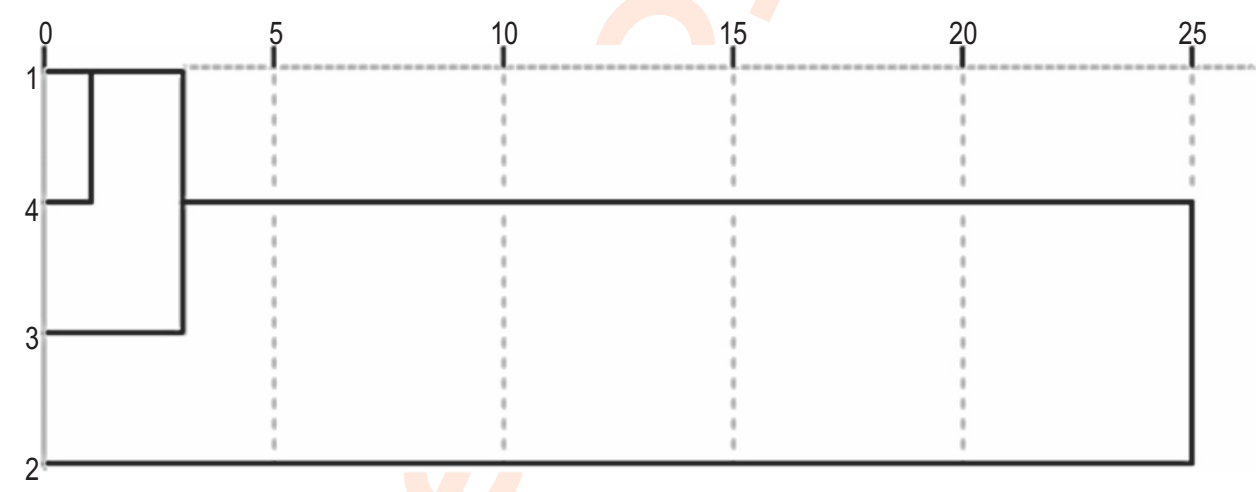

Fig. 3 : UPGMA dendrogram prepared by using morphometric (conventional and truss) characters of M. aculeatus. DBJ: Dhakuriabeel, Jashore; AKRM: Arial khan River, Madaripur; NRJ: Nabaganga River, Jhenidah and KRJ: Kopotakkha river, Jashore.

morphometric and truss measurements shown in four populaces. Where, two clusters were mainly formed in the Euclidian dendrogram, in which first cluster was formed by AKRM and second cluster was formed by two populations namely DBJ and NRJ and finally KRJ formed another subcluster with DBJ (Fig. 3). Dendrogram clearly revealed that AKRM population showed a clear separation and formed a distinct population due to its variant morphometric characters, while NRJ and DBJ aggregately formed a separate cluster due to similar morphometric characters which is strongly supported by discriminant function analysis as well as classification results (Fig 2). Additionally, the morphometric similarity was clearly observed in KRJ and DBJ populations when compared with other populations.

In the morphometric investigations, highly significant morphological variations were found in four populations where SL, BD, UJL, LJL, HD, IO, 1-2, 2-3, 6-7, 7-8, 1-8, 3-8, 3-7, 4-6, 4-8 and 5-7 characters showed significant deviations among the populations. These univariate statistics differences completely matched with the previous experiment conducted following same procedure by Mahfujet al. (2019) for Macrognathus pancalus collected from four South-western Bangadeshi fresh waters namely, NRJ, AKRM, DBJ and BoluharpurBaor in Jhenaidah district. Furthermore, three discriminant functions were created in the present study, where 6-7, UJL, 2-3, 3-8 characters uniquely contributed to DF1; $1-8,1-2,4-5$ characters are commonly shared in DF2; and finally $\mathrm{HD}, 4-8,3-7$ characters normally matched in DF3 linked by Mahfujet al. (2019) for Macrognathus pancalus. Arranging discriminant function DF1, DF2 and DF3 displayed a clear accumulation amongst the individuals and the populations for both morphometric and landmark dimensions. Four populaces were clearly amalgamated from each other in the discriminant biplot space. It elucidated and demonstrated that first DF was more useful than the second DF. Third DF was consequently less explanatory in the explaining differences among the stock. This information suggested that there was intermingling among the populations. It disclosed that the discriminant exploration was appropriate as useful technique for classifying populaces, strains, and subspecies, which have close associations.

Morphometric alterations among populations are highly predictable because of environmental variations changes from 
place to place (Hossain et al., 2010; Gain et al., 2017; Mahfuj et al., 2017). Phenotypic differences among four populations may be due to their distinct geographical place, prevailing environmental deviation of their habitats or these populations may be initiated from diverse lineages (Poulet et al., 2005). Fish demonstrates subtle to environmental vicissitudes and acclimate rapidly by changing phenotypes. Morphological characters showed that high plasticity occurs due to environmental condition such as food abundance and day degree temperature (Allendorf and Phelps, 1980; Swain et al., 1991, Wimberger, 1992). Usually, fish displays superior adjustments in morphological charms populations levels than other vertebrates and are more vulnerable to biologically induced morphological disparities (Wimberger, 1992). The phenotypic variations among the samples could be implied as strong togetherness between phenotypic disparity and geographic partition that might be an indicator of limited intermingling factor for migration among four populations. Similar findings were reported by (Esen and Ahmet, 2010) in Mastacembelus mastacembelus. Environmentally persuaded phenotypic variation may have gratified in the stock structure investigation of exploited species, particularly when time is inadequate.

It is noted that, obvious deterioration from the wild sources of spiny eel in the Bangladesh sub-continent. Consistent information and research of morpho-variation and stock structure are vital for the management and conservation of species. The consequences of research are beneficial for baseline evidence of M. aculeatus for supplementary studies in both aquaculture and management. Therefore, it is highly indispensable to select genetically superior stocks along with better heritability. More investigation, particularly on genetics studies and inquiries on the impact of environmental factors is desired for preservation of near threatened spices. The standard data obtained from the present study would be convenient for the maintenance of diminishing stocks of spiny eel, M. aculeatus.

\section{Add-on Information}

Authors' contribution : M. Sarower-E-Mahfuj, S.K. Das, K.N. Azad, A.K. Paul: Conceptualization of study, drafting manuscript, data analysis, results interpretation, editing and organizing the final version of the manuscript, I. Hoshan, S. Sultana and M. Biswas: Aata analysis, results interpretation, and organizing the final version of the manuscript.

Research content : The research content of manuscript is original and has not been published elsewhere.

\section{Ethical approval : NotApplicable}

Conflict of interest : The authors declare that there is no conflict of interest.

\section{Data from other sources : NotApplicable}

Consent to publish : All authors agree to publish the paper in Journal of Environmental Biology.

\section{References}

Ahmed, M.S. and H. Akther: Brush and vegetation park fishery in the river Titas, Brahmanbaria, Bangladesh. South Pac. Stud., 29, 63-71 (2008).

Allendorf, F.W. and S.R. Phelps: Loss of genetic variation in a hatchery stock of cutthroat trout. T.Am. Fish. Soc., 109, 537-543 (1980).

Barriga-Sosa, I., M.D.L. Jiménez-Badillo, A.L. Ibáñez and J.L. Arredondo-Figueroa: Variability of tilapias (Oreochromis spp.) introduced in Mexico: Morphometric, meristic and genetic characters. J. Appl. Ichthyol., 20, 7-14 (2004).

Cadrin, S.X. and K.D. Friedland: The utility of image processing techniques for morphometric analysis and stock identification. Fish. Res., 43, 129-139 (1999).

Çakmak, E. and A. Alp: Morphological differences among the Mesopotamian spiny eel, Mastacembelus mastacembelus (Banks and Solander 1794), populations. Turkish J. Fish. Aquat. Sci., 10, 87-92 (2010).

Chaklader, M.R., A. Nahar, M.A. Hanif and M.A. Siddik: Intraspecific morphometric diversity of barramundi (Latescalcarifer Bloch, $1790)$ in the waters of Southern Bangladesh. J. Ocean. Limnol., 37, 1393-1402 (2019).

Elliott, N.G., K. Haskard and J.A. Koslow: Morphometric analysis of orange roughy (Hoplostethus atlanticus) off the continental slope of southern Australia. J. Fish Biol.,46, 202-220 (1995).

Esen, Ç. and A. Ahmet: Morphological differences among the mesopotamianspiny eel, Mastacembelus mastacembelus (Banks and Solander 1794), populations. Turkish J. Fish. Aquat. Sci., 10, 87-92 (2010).

Gain, D., M.S. Mahfuj, K.A. Huq, S.S. Islam, M.H. Minar, M.P. GouthamBharathi and S.K. Das: Landmark-based morphometric and meristic variations of endangered Mrigal carp, Cirrhinuscirrhosus (Bloch 1795), from wild and hatchery stocks. Sains Malays., 46, 695-702 (2017).

Hanif, M.A., M.R. Chaklader, M.A. Siddik, A. Nahar, M.J. Foysal and R. Kleindienst: Phenotypic variation of gizzard shad, Anodontostomachacunda (Hamilton, 1822) based on truss network model. Reg. Stud. Mar. Sci., 25, 100442 (2019).

Hossain, M.A., M. Nahiduzzaman, D. Saha, M.U.H. Khanam and M.S. Alam: Landmark-based morphometric and meristic variations of the endangered Carp, KalibausLabeocalbasu, from stocks of two isolated rivers, the Jamuna and Halda, and a hatchery. Zool. Stud., 49, 556-563 (2010).

Hubbs, C.L.: Variations in the number of vertebrae and other meristic charactersoffishes correlated with the temperature of water during development. Am. Nat., 56, 360-372 (1922).

IUCN-Bangladesh: Red List of Bangladesh. Volume 5: Freshwater Fishes. IUCN, Bangladesh Country Office, Dhaka, Bangladesh, p. 360 (2015).

Kaneko, K.: Relationship among phenotypic plasticity, phenotypic fluctuations, robustness, and evolvability; Waddington's legacy revisited under the spirit of Einstein. J. Biosci., 34, 529-542 (2009).

Kashefi, P., A. Bani and E. Ebrahimi: Morphometric and meristic variations between non-reproductive and reproductive kutum females (Rutilusfrisiikutum, Kamensky, 1901), in the South-west Caspian Sea. Ital. J. Zool.,79, 337-343 (2012). 
Leary, R.F., F.W. Allendorf and K.L. Knudsen: Effects of rearing density on meristicsand developmental stability of rainbow trout. Copeia, 1991, 44-49(1991).

Lindsey, C.C.: 3 Factors controlling meristic variation. In: Fish Physiology (Eds.: W.S. Hoar andD.J. Randall). Academic Press, pp. 197-274 (1988).

Mahfuj, M.S., M.A. Ashraful, I. Parvez, M.H. Minar and M.A. Samad: Morphological variations of Labeobata populations (Teleostei: Cyprinidae) in six rivers of Bangladesh: A landmark-morphometric contribution. Iran. J. Ichthyol., 4, 270-280 (2017).

Mahfuj, M., A. Khatun, P. Boidya, and M.A. Samad: Meristic and morphometric variations of barred spiny eel Macrognathus pancalus Populations from Bangladeshi Freshwaters: An insight into landmark-based truss network system. Croat. J. Fish., 77, 718 (2019).

Mahmud, A.I., Y.A. Patwary, M.R.I. Sarder and M.F.A. Mollah: Morphometric and meristic characteristics and some aspects of reproductive biology of spiny eel, Mastacembelu sarmatus (Lacepede, 1800). P. Natl. A. Sci. India B., 88, 339-353 (2018).

McHugh, J.L.: The influence of light on the number of vertebrae in the grunion, Leuresthes tenuis. Copeia, 1954, 23-25(1954).

Melvin, G.D., M.J. Dadswell and J.A. McKenzie: Usefulness of meristic and morphometric characters in discriminating populations of American shad (Alosasapidissima) (Ostreichthyes: Clupeidae) inhabiting a marine environment. Can. J. Fish. Aquat. Sci., 49, 266280 (1992).

Narejo, N.T., S.M. Rahmatullah and M.M. Rashid: Length - weight relationship and relative condition factor $(\mathrm{Kn})$ of freshwater spiny eel, Mastacembelus armatus (Lacepede) from Mymensingh, Bangladesh. Ind. J. Fish., 50, 81-87 (2003).

Pathak B.C., J.I. Mir and M. Serajuddin: Morphometric variation among barred spiny eel, Macrognathus pancalus (Hamilton 1822), Populations from the Ganges and Brahmaputra River Basin, India by using geomorphometrics. Res. J. Biol., 3, 15-20 (2013).

Plamoottil, M. and N.P. Abraham: Macrognathus albus (Order: Synbranchiformes; Family: Mastacembelidae), a new fish species from Kerala, India. Int. J. Pure Appl. Zool., 2, 100-105 (2014).

Pinheiro, A., C.M. Teixeira, A.L. Rego, J.F. Marques and H.N. Cabral: Genetic and morphological variation of Solealascaris (Risso, 1810) along the Portuguese coast. Fish. Res., 73, 67-78 (2005).
Poulet, N., Y. Reyjol, H. Collier and S. Lek: Does fish scale morphology allow the identification of populations at a local scale? A case study for rostrum dace Leuciscus burdigalensis in River Viaur (SW France). Archiv. Hydrobiol., 67, 122-127 (2005).

Rohlf, F.J.: TPS software series. Department of Ecology and Evolution, State University of New York, Stony Brook, NY, USA (2006).

Saha, B.K.: Macrognathus aculeatus. In: Encyclopedia of Flora and Fauna of Bangladesh: Freshwater Fishes. (Eds.: K.U. Siddiqui, M.A. Islam, S.M.H. Kabir, M. Ahmad, A.T.A. Ahmed, A.K.A. Rahman, E.U. Haque, Z.U. Ahmed, Z.N.T. Begum, M.A. Hasan, M. Khondker and M.M. Rahman). Vol. 23, Asiatic Society of Bangladesh, Dhaka, Bangladesh, p. 235 (2007).

Strauss, R.E., and C.E. Bond: Taxonomic methods: Morphology. In: Methods for Fish Biology (Eds.: P. Moyle, C. Schreck). Amer. Fish. Soc., pp. 109-140 (1990).

Strauss, R.E. and F.L. Bookstein: The Truss: Body form reconstructions in morphometrics. Syst. Biol., 31, 113-135 (1982).

Sultana, S., K. Nahar, J. Bir, M. Kabiraj and M.N. Khan: A quick view on biology of near threatened peacock eel (Macrognathus aculeatus) in Khulna region of Bangladesh. Am. J. Zool. Res., 5, 38-46 (2017).

Swain, D.P. and C.J. Foote: Stocks and chameleons: The use of phenotypic variation in stock identification. Fish. Res., 43, 113-128 (1999).

Swain, D.P., B.E. Riddell and C.B. Murray: Morphological differences between hatchery and wild populations of Coho salmon (Oncorhynchus kisutch): environmental versus genetic origin. Can. J. Fish. Aquat. Sci., 48, 1783-1791 (1991).

Swain, D.P., J.A. Hutchings and C.J. Foote: Environmental and genetic influences on stock identification characters. In: Stock Identification Methods: Applications in Fishery Science (Eds.: S.X. Cadrin, K.D. Friedland and J.R. Waldman). Elsevier, Amsterdam, Netherlands (2005).

Vladykov, V.D.: Environmental and taxonomic characters of fishes. Trans. R.Can.Inst., 20, 99-140 (1934).

Waldman, J.R.: Meristics. In: Stock Identification Methods: Applications in Fishery Science (Eds.: S.X. Cadrin, K.D. Friedland and J.R. Waldman). Elsevier, Amsterdam, Netherlands (2005).

Wimberger, P.H.: Plasticity of fish body shape. The effects of diet, development, family and age in two species of Geophagus (Pisces: Cichlidae). Biol. J. Linn. Soc., 45, 197-218 (1992). 